\title{
SYMPOSIUM
}

\section{The effect of HIV, behavioural change, and STD syndromic management on STD epidemiology in sub-Saharan Africa: simulations of Uganda}

\author{
E L Korenromp, R Bakker, R Gray, M J Wawer, D Serwadda, J D F Habbema
}

Sex Transm Infect 2002;78(Suppl I):i55-i63

An assessment was made of how the HIV epidemic may have influenced sexually transmitted disease (STD) epidemiology in Uganda, and how HIV would affect the effectiveness of syndromic STD treatment programmes during different stages of the epidemic. The dynamic transmission model STDSIM was used to simulate the spread of HIV and four bacterial and one viral STD. Model parameters were quantified using demographic, behavioural, and epidemiological data from rural Rakai and other Ugandan populations. The findings suggest that severe HIV epidemics can markedly alter STD epidemiology, especially if accompanied by a behavioural response. Likely declines in bacterial causes of genital ulcers should be considered in defining policies on syndromic STD management in severe HIV epidemics.

See end of article for authors' affiliations

Correspondence to:

Correspondence to:
Dr E L Korenromp, Erasmus University Rotterdam, Department of Public Health, PO Box 1738, 3000 DR Rotterdam, the Netherlands;

korenromp@mgz.fgg.eur.nl; korenrompe@who.int

Accepted

30 November 2001
T hroughout the recent history of sub-Saharan Africa, sexually transmitted diseases (STD) have been a major cause of mortality and morbidity. ${ }^{1-3}$ Colonial and postcolonial socioeconomic and behavioural changes, as well as developments in biomedical sciences and health care, have markedly affected STD epidemiology in the 20th century. $^{1245}$ The rapid growth of cities, with extensive migration from rural to urban areas, especially by men without their families, may have contributed to rapid STD spread by increasing the practice of prostitution. ${ }^{1}$ In the 1950s and 1960s, penicillin probably helped to control the spread of syphilis. The use of penicillin against STDs and other illnesses is also likely to have reduced gonorrhoea during that period, which may have contributed to declines in infertility. ${ }^{45}$ However, gonorrhoea resistance to penicillin developed rapidly, and gonorrhoea rates appear to have remained high up till the 1980s. ${ }^{16}$ For some areas, including central Africa, increased school attendance probably contributed to STD reductions through declines in sexual activity by adolescent girls. ${ }^{5}$ During the 1960s and 1970s, (civil) wars, social instability, and population movements in response to natural disasters may have enhanced sexual mixing, providing a further mechanism for STDs to spread again (and probably for HIV to start spreading), for example in Uganda and Kenya. ${ }^{278}$ In summary, despite some possible temporary successes in the control of some STD, before the 1980s the contribution of public health interventions to curbing STD spread seems in sub-Saharan Africa to have been limited. Consequently, during this period, STD epidemiology in sub-Saharan Africa does not conform to the sequence of stages of increasing control observed in Western industrialised countries. ${ }^{9}$

Since the HIV pandemic, STDs and their control in sub-Saharan Africa have received increasing attention. Following the insight that STD, as well as being a marker of sexual (risk) activity, may enhance HIV transmission, ${ }^{10-15}$ HIV prevention policies have adopted STD management as an essential component of prevention programmes. ${ }^{16}$ STD surveillance was recognised as a useful comparison of HIV risk assessment, both for identifying the population subgroups most at risk and for monitoring time trends in risk behaviour. Subsequently, several subSaharan Africa countries reported falls in the rates of STD. Interestingly, some STDs appear to be more affected than others, with decreases in chancroid being noted most often ${ }^{17-21}$; for ulcerations caused by herpes simplex virus type 2 (HSV-2), on the other hand, increases have been noted, at least among clinic patients and selected survey populations. ${ }^{18} 2022-24$

In this paper, we assess how severe HIV epidemics as encountered in several sub-Saharan Africa countries may influence the epidemiology and control of STDs. We used the epidemiological transmission model STDSIM ( simulation model for STD control) to simulate the spread of HIV and STDs and interactions between these infections. ${ }^{25}{ }^{26}$ The model was quantified to represent Uganda, which was one of the first countries recognising a severe HIV epidemic ${ }^{27-29}$ and, following the end of its civil war in 1986, to adopt a national AIDS control policy including large scale implementation of IEC programmes and voluntary HIV testing and counselling. During the early 1990s, Uganda was again one of the first countries to see behavioural risk reduction at a population level. ${ }^{30-36}$ In parallel, HIV prevalence stabilised and appears to have started a slow decline in these regions since the mid-1990s. ${ }^{31-33}{ }^{37-40}$ To understand the effects of HIV epidemiology and behavioural change on STD epidemiology and control, we simulated HIV and STD epidemiology and the effectiveness of intervention programmes involving improved STD management over time, both for Uganda and for a hypothetical population without any behaviour change.

\section{METHODS}

\section{STDSIM model}

STDSIM simulates the natural history and transmission of several STDs and HIV, in a dynamic 
Table 1 Representation of natural history and transmission of HIV and sexually transmitted diseases in the STDSIM simulation of the Uganda HIV epidemic

\begin{tabular}{|c|c|c|c|c|c|c|}
\hline \multirow[b]{2}{*}{ Infection and stage } & \multirow[b]{2}{*}{ Mean duration* } & \multicolumn{2}{|c|}{ Transmission probability $\dagger$} & \multirow{2}{*}{$\begin{array}{l}\text { Cofactor effect on HIV } \\
\text { transmissiont‡ }\end{array}$} & \multicolumn{2}{|c|}{$\begin{array}{l}\text { Proportion } \\
\text { symptomatic }\end{array}$} \\
\hline & & $M \Rightarrow F$ & $\mathrm{~F} \Rightarrow \mathrm{M}$ & & M & $\mathrm{F}$ \\
\hline \multicolumn{7}{|l|}{ HIV } \\
\hline Primary & 10 weeks & 0.045 & 0.015 & na & na & na \\
\hline Asymptomatic & 5 years & 0.00225 & 0.00075 & na & na & na \\
\hline Symptomatic pre-AIDS & 2 years & 0.00225 & 0.00075 & na & na & na \\
\hline AIDS & 40 weeks & 0.01125 & 0.00375 & na & na & na \\
\hline \multicolumn{7}{|l|}{ Syphilis } \\
\hline Infectious & 6 months & 0.3 & 0.2 & $10 x$ & $80 \%$ & $50 \%$ \\
\hline Latent & 15 years & 0 & 0 & na & na & na \\
\hline Chancroid & 10 weeks & 0.20 & 0.15 & $25 x$ & $90 \%$ & $70 \%$ \\
\hline \multicolumn{7}{|l|}{ HSV-2 } \\
\hline Primary ulcer & 3 weeks & 0.30 & 0.15 & $25 x$ & $30 \%$ & \\
\hline Early latent (with recurrent ulcers) & 15 years & $0.005 \S$ & $0.0025 \S$ & na§ & naß & naई \\
\hline Recurrent ulcer & $\begin{array}{l}1 \text { week; } \\
\text { Interval between ulcers } 6 \text { months }\end{array}$ & 0.20 & 0.10 & $10 x$ & $15 \%$ & $7.5 \%$ \\
\hline Late latent & Lifelong & 0 & 0 & na & na & na \\
\hline Gonorrhoea & $\begin{array}{l}\text { M9 weeks; } \\
\text { F } 13 \text { weeks }\end{array}$ & 0.22 & 0.15 & $5 \times$ & $50 \%$ & $20 \%$ \\
\hline Chlamydia & $\begin{array}{l}\text { M } 12 \text { weeks; } \\
\text { F } 16 \text { weeks }\end{array}$ & 0.20 & 0.12 & $5 \times$ & $30 \%$ & $15 \%$ \\
\hline $\begin{array}{l}\text { *Individual stage durations were san } \\
\text { HSV-2 and the interval between recu } \\
\text { unrecognized episodes; fboth for su } \\
\text { F, female; } M \text {, male; na, not applicak }\end{array}$ & $\begin{array}{l}\text { led from a Weibull distribution fur } \\
\text { ent HSV-2 ulcers, which used expo } \\
\text { eptibility (in HIV negative partner) } \\
\text {. }\end{array}$ & $\begin{array}{l}\text { with sha } \\
\text { tial distribu } \\
\text { infectivity }\end{array}$ & $\begin{array}{l}\text { rameter } 2, \\
\text { unctions; } t p \\
\text { V positive }\end{array}$ & $\begin{array}{l}\text { for the duration of the e } \\
\text { ntact; equal for recogniz } \\
\text { r); §except during recurre }\end{array}$ & $\begin{array}{l}\text { arly late } \\
\mathrm{d} \text { and } \\
\text { nt ulce }\end{array}$ & age of \\
\hline
\end{tabular}

population defined by a detailed set of parameters. The model population consists of individuals with assigned characteristics that change over time. The formation and dissolution of heterosexual partnerships between individuals, and the transmission of STDs during contacts between sexual partners, are modelled as stochastic events. ${ }^{26}{ }^{41}$ Recently, the model was adapted to include the simulation of genital infection with HSV-2 and the effects of HIV infection on the natural history and transmission of STDs including HSV-2. The adapted model allowed us to study the epidemiology of curable and incurable STDs in relation to HIV.

\section{Simulated populations}

The simulation of the HIV/STD epidemic in Uganda was based on data collected in rural Rakai district, Uganda, in the context of an STD treatment trial and preceding cohort studies, ${ }^{28} 3942-45$ and previous simulations ${ }^{41}$ of an STD treatment trial in rural Mwanza, Tanzania, which also involved a rural population. ${ }^{46}{ }^{47}$ Few data are available on sexual behaviour in either Uganda or Tanzania before 1989, the time of the first HIV related surveys. Two assumptions were made to explain the much higher prevalence of HIV in Uganda than in Tanzania in 1989 (15-25\% as compared to 2.5\%). ${ }^{39} 4548$ First, we estimated that HIV spread had started relatively early in Uganda. Because the time of HIV introduction in Uganda is not precisely known and the first AIDS cases were observed in $1982,{ }^{27}$ this timepoint was set at 1978, around the time of the Tanzanian invasion and the start of the civil war. Second, we assumed that partner change rates had been higher and one-off contacts more frequent in Uganda during the period of civil war between 1978 and 1986, reflecting social disruption. Compared with the first Ugandan behavioural surveys in the late 1980s, behavioural risk reductions have been observed during the 1990s. Reported changes include reductions in numbers of partners, increased condom use, especially in the younger age groups, and possibly delays in the age of first sex. ${ }^{30-34}$ There is anecdotal evidence that in Rakai trading centres, commercial sex had become less common in the 1990s compared with the 1980s. ${ }^{45}$

These behavioural changes were represented in the model as a $50 \%$ reduction in the proportion of males having one-off sexual contacts (for example with female sex workers) after 1986. In addition, a $25 \%$ reduction in partner change rates in the whole population was assumed after this time. This quantification resulted in adequate fit of the model with respect to proportions married, numbers of recent partners of men, and age/sex patterns in data from rural Rakai in 1995 (not shown). It is of note, however, that the exact magnitudes of change assumed in the model may be arbitrary, because the two simulated types of risk behaviour are a simplistic representation of a spectrum ranging from "hard core prostitution" through non-commercial one-off contacts and even rape, to long term relationships with high contact frequency. For the hypothetical Uganda-like population without behavioural risk reduction, the assumed behavioural changes in 1986 were omitted from the simulation.

\section{Assumptions on natural history and transmission of STD}

The STDSIM representations of STD natural history and transmission were based on a review of the scientific literature and are shown in table 1. The parameterisation for gonorrhoea and chlamydia has been described before. ${ }^{41}$

The representation of HSV-2, which resulted in realistic age/sex patterns in simulated HSV-2 seroprevalence, has been described elsewhere. ${ }^{49}$ In brief, the infection was specified to start with a primary ulcer lasting for a mean of three weeks. ${ }^{50-54}$ After healing of this lesion, ulcers would recur at an average six months interval ${ }^{55} 56$ for a period of, on average, 15 years, denoted the "early latent stage". In line with their relative clinical severity, ${ }^{54}$ herpetic recurrences were assumed to be less severe in terms of symptoms and infectivity than primary ulcers. In between recurrences, a low continuous level of infectivity was assumed, which represented the regular occurrence of episodes of subclinical shedding in the majority of HSV-2 infectees. ${ }^{57-61}$ By the end of the "early latent stage" patients were assumed no longer to suffer recurrences nor to be infectious, but to remain seropositive for life.

Chancroid was represented as a continuous ulcerative episode lasting on average 10 weeks. ${ }^{62}{ }^{63}$ Transmission probabilities were specified at a lower level (15-20\%; table 1) than the single available empirical estimate $(43 \%$, for male to female transmission $\left.{ }^{64}\right)$. This was done in order to have the 
model predict a realistic prevalence level and a realistic fraction of ulcers attributable to chancroid (see Results). The downward adjustment also served as a simplistic representation of reduced sexual activity during painful ulcers, which was not explicitly modelled.

Syphilis was represented by two consecutive stages, with the first, the "infectious" stage, corresponding roughly to primary and secondary syphilis. ${ }^{65}$ In the absence of effective treatment, syphilis patients progress to a non-infectious "latent" stage. For computations of ulcer incidence, we assumed that each syphilis infection causes two ulcers during the infectious stage. Syphilitic ulcers were specified to be less often symptomatic relative to chancroid. ${ }^{66-68}$

HIV infection was specified as four subsequent stages, named primary HIV infection, asymptomatic stage, symptomatic pre-AIDS stage, and AIDS. These stages, which were defined according to relative levels of viral shedding and symptomatology, ${ }^{69-72}$ differed in their relative infectivity as well as in their effect on ulcerations caused by HSV-2 (see below). HIV transmission probabilities were modelled in a "bath tub" pattern, with infectivity being highest during primary HIV disease and during AIDS. ${ }^{70} 7173$ Sexual activity and frequency of intercourse were assumed not to be altered during the symptomatic stages of HIV infection.

\section{Interactions between STDs and HIV}

We assumed that STDs enhance the infectivity with HIV and the susceptibility to HIV, by a factor varying with the disease stage (table 1). In the absence of knowledge on STD cofactor magnitudes from experimental studies, we estimated these variables from mathematical calculations, based on observational studies among commercial sex workers and clients in Nairobi. ${ }^{74}{ }^{75}$ In line with recent insights, ${ }^{75}$ the resulting cofactor values were lower than those assumed in previous model studies. In case of multiple cofactors (for example, one partner in an HIV discordant couple with multiple concurrent STDs, or both partners with one or more STDs), the maximum cofactor for any single STD applied. The relative cofactor magnitudes of different ulcerative STDs were chosen in line with their relative clinical severity. For the infectious stage of syphilis, during which several ulcer episodes may occur intermittently, ${ }^{65}$ an average cofactor effect of 10 -fold was applied throughout.

Besides cofactor effects of STDs on HIV transmission, interactions between HIV and STD may include an effect of immunosuppression during advanced HIV disease on the duration and frequency of herpetic ulcers. ${ }^{13}{ }^{76}$ HIV disease is associated with three- to fourfold increases in the number of culture positive days ${ }^{77-80}$ and the incidence of clinical ulcers, ${ }^{81}$ part of which may reflect the fact that ulcer episodes last longer. ${ }^{79}$ In line with these data, we assumed that during the symptomatic stages of HIV infection (table 1), the duration and the frequency of recurrent herpetic ulcers, as well as the remaining duration of the early latent stage (during which ulcers recur), are doubled. Possible effects of HIV on the natural history of chancroid and syphilis ${ }^{13}$ were ignored.

\section{STD intervention}

The simulated STD intervention increased the cure rate of symptomatic episodes of gonorrhoea, chlamydia, syphilis, and chancroid from $5 \%$ to $38 \%$. This figure was based on estimates of coverage and cure rates in a trial of syndromic STD treatment in Mwanza, Tanzania. ${ }^{82}$ As a simplification in the model, only the symptomatic STD for which the patient sought treatment was cured; concurrent asymptomatic infections were not. The simulated intervention was initiated in 1981, 1988, or 1998 (the third, 10th, or 20th year of the HIV epidemic, respectively), and was sustained throughout the simulation period.

\section{Simulation design}

In order to reduce random fluctuations associated with stochastic simulations, 100 simulation runs were conducted for each scenario. All outcomes are reported as averages over 100 runs, in the general adult population aged 15-49 years.

\section{RESULTS}

Uganda epidemic and influence of behaviour change

Figure 1 shows the simulated prevalence of STDs and HIV over time for Uganda and in the hypothetical Uganda-like population without behavioural change. The simulated prevalences
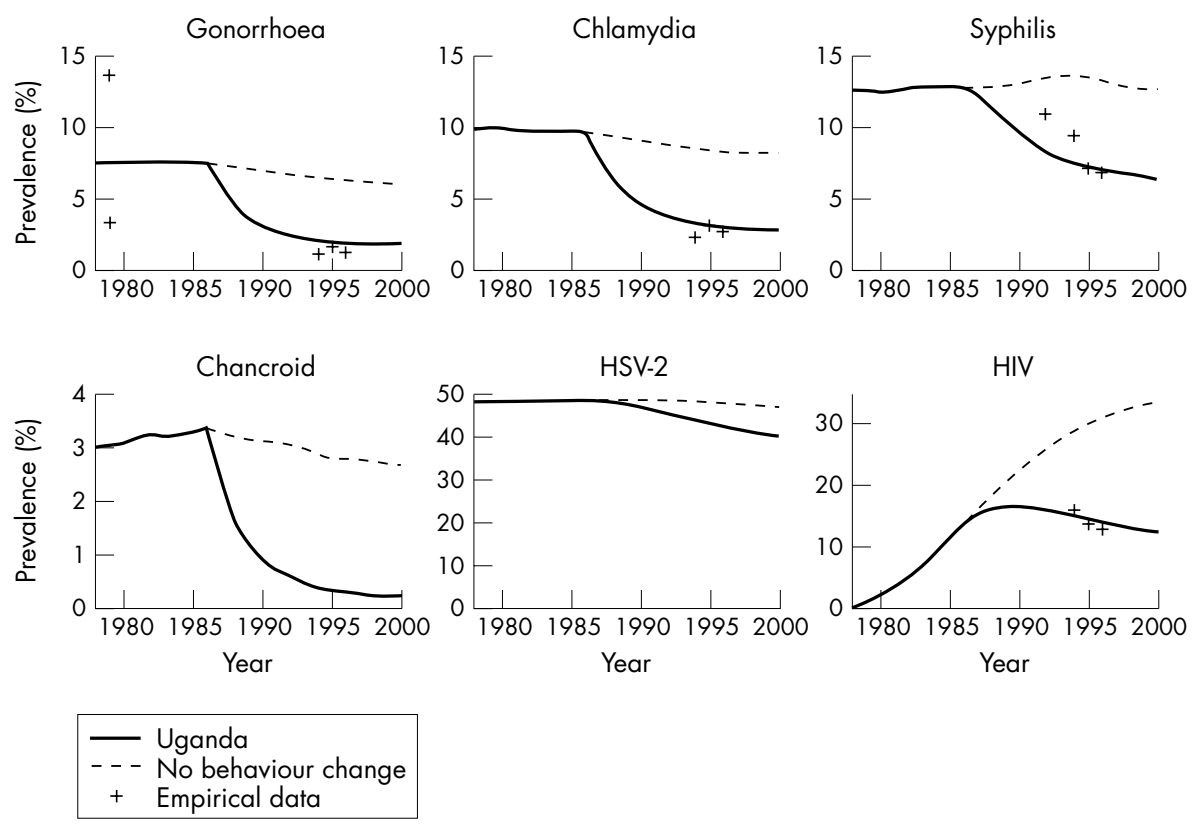

Figure 1 Simulated prevalences (\%) of sexually transmitted diseases and HIV in adults ( 15 to 49 years), for rural Uganda and a hypothetical Uganda-like population without a behaviour change. Syphilis: RPR+/TPHA+ any titre ${ }^{83}$; HSV-2: seroprevalence. Mean of 100 simulated populations. Empirical data, for comparison, for 1992-96 from rural Rakai (baseline comparison arm in STD mass treatment trial and pretrial cohort study; for gonorrhoea and chlamydia 1994-96: subsample aged 15 to 29 years; gonorrhoea data 1979: random subsamples of the general adult population in 1971-72 in rural Ankola and Teso districts 6 ). 
of gonorrhoea and chlamydia between 1994 and 1996 in the Uganda simulation are in line with data from Rakai (fig 1, panels A and B) ${ }^{83}$ The simulated prevalence of syphilis (fig IC) matches that measured in Rakai between 1994 and 1996, and the simulated stage distribution-with the majority of prevalent cases being in late syphilis stages-was in line with the observed low RPR titres in infected cases in Rakai. In addition, simulated age specific seroprevalence of HSV-2 (fig lE) is consistent with empirical data for the male and female population aged 15 to 29 years from Rakai and for males and females of all ages from neighbouring rural Masaka (not shown). ${ }^{84}$

After 1986, STD prevalences fall in the Uganda simulation, following the assumed behavioural risk reduction in 1986 ( fig 1 , panels A-E). The simulated decline in syphilis prevalence matches that observed in Rakai between 1992 and 1996, although it is somewhat too early. The simulated prevalence fall is fastest and largest for chancroid. Because chancroid has the lowest reproductive number, control strategies of moderate intensity-like the assumed behavioural change-can have most impact on this STD. ${ }^{85}$ The prevalence decline is comparatively slow and small for HSV-2 (from $48 \%$ to $43 \%$ in 1995), for two reasons. As HSV-2 is a lifelong infection with a high baseline prevalence and recurrent nature, a reduction in herpetic ulceration can only follow from reductions in new infections in the youngest age groups. Thus reduced HSV-2 transmission takes a long time to affect HSV-2 seroprevalence at a population level. Furthermore, the behavioural effect is to some extent counterbalanced by the assumed enhancement of herpetic ulceration in HIV patients, which acts to increase HSV-2 transmission.

HIV prevalence in the Uganda simulation peaks at $17 \%$ around 1990, after which it stabilises and starts a slow decline, in line with trends in assumed risk behaviour and STD rates (fig $1 F$ ). This level and time trend matches observations between 1994 and 1996 in Rakai. ${ }^{28} 3944$ The simulated stable HIV prevalence level between 1989 and 1992 matches the stability observed in earlier prevalence studies in Rakai, neighbouring rural Masaka ${ }^{33}$ and Kampala. ${ }^{32} 4086$

In the hypothetical population without behavioural change, prevalences of the bacterial STD also decrease during the 1990s, but only moderately (fig l, panels A-D). These declines result from excess HIV related mortality in high risk groups, which lowers the overall level of risk behaviour in the population. The decline is most pronounced for chancroid, for which prevalence falls from $3.1 \%$ in 1990 to $2.7 \%$ by 2000 . The prevalence of HSV-2, in contrast, remains stable at $48 \%$ throughout the HIV epidemic in this scenario (fig IE), owing to the counterbalancing effect of enhanced herpetic ulceration in HIV patients.

\section{Effect of the HIV epidemic on STD spectrum}

In order to assess the implications of HIV induced changes in STD spectrum for STD management, we examined the incidence and distribution of cases of ulcerative and nonulcerative STD over the different aetiologies. To do this, we derived distributions of aetiologies of incident syndromes, based on simulated incidence of herpetic and syphilitic ulcers, and episodes of chancroid, gonorrhoea, and chlamydia. For comparison between simulation outcomes and data from STD clinic populations, we focus on recognised STD syndromes, using the symptom recognition probabilities shown in table 1 .

Before the HIV epidemic, the majority $(62 \%)$ of incident recognised genital ulcer disease (GUD) in the simulated population are caused by chancroid (fig 2A), while $29 \%$ and $9 \%$, respectively, are caused by HSV-2 and syphilis.

By year 2000 in the Uganda epidemic, the incidence of chancroid has fallen markedly as a result of the behaviour change; consequently the proportion of GUD due to chancroid has decreased to $13 \%$. The proportion of incident GUD attributed to syphilis is relatively constant throughout the epidemic
(9-12\%). Among ulcers of bacterial origin, syphilis accounts for only $12 \%$ of cases before the HIV epidemic, the remainder being accounted for by chancroid. Owing to the larger fall in chancroid relative to syphilis upon behaviour change, by year 2000 almost half of bacterial ulcers are caused by syphilis.

Because of the relatively large falls in syphilis and especially chancroid, the proportion of GUD attributed to herpes increases to $75 \%$ in 2000 . This effect is enhanced by an absolute increase in the incidence of herpetic ulcers, resulting from the assumed increase in herpetic ulceration in HIV patients.

Of the simulated non-ulcerative STDs, chlamydia and gonorrhoea cause about $35 \%$ and $65 \%$ of episodes of recognised genital discharge/dysuria, respectively, before the HIV epidemic (fig 2B). In the model, these two infections accounted for all urethritis and cervicitis morbidity, because other genital tract infections like trichomonas and bacterial vaginosis were not simulated. Over the course of the HIV epidemic, chlamydia would become slightly more important relative to gonorrhoea, accounting for $38 \%$ of non-ulcerative STD episodes by 2000 in the Uganda simulation. This is because chlamydia rates fall less with behaviour change than gonorrhoea rates (fig l, panels A and B). Overall, the proportion of ulcerative STD among all incident recognised STDs increases from 51\% to 59\% during the Uganda epidemic.

The simulated shift in STD distribution reflects the time trends in the prevalence of the respective STD (fig l, panels C, $\mathrm{D}$, and $\mathrm{E}$ ). In the hypothetical population without behaviour
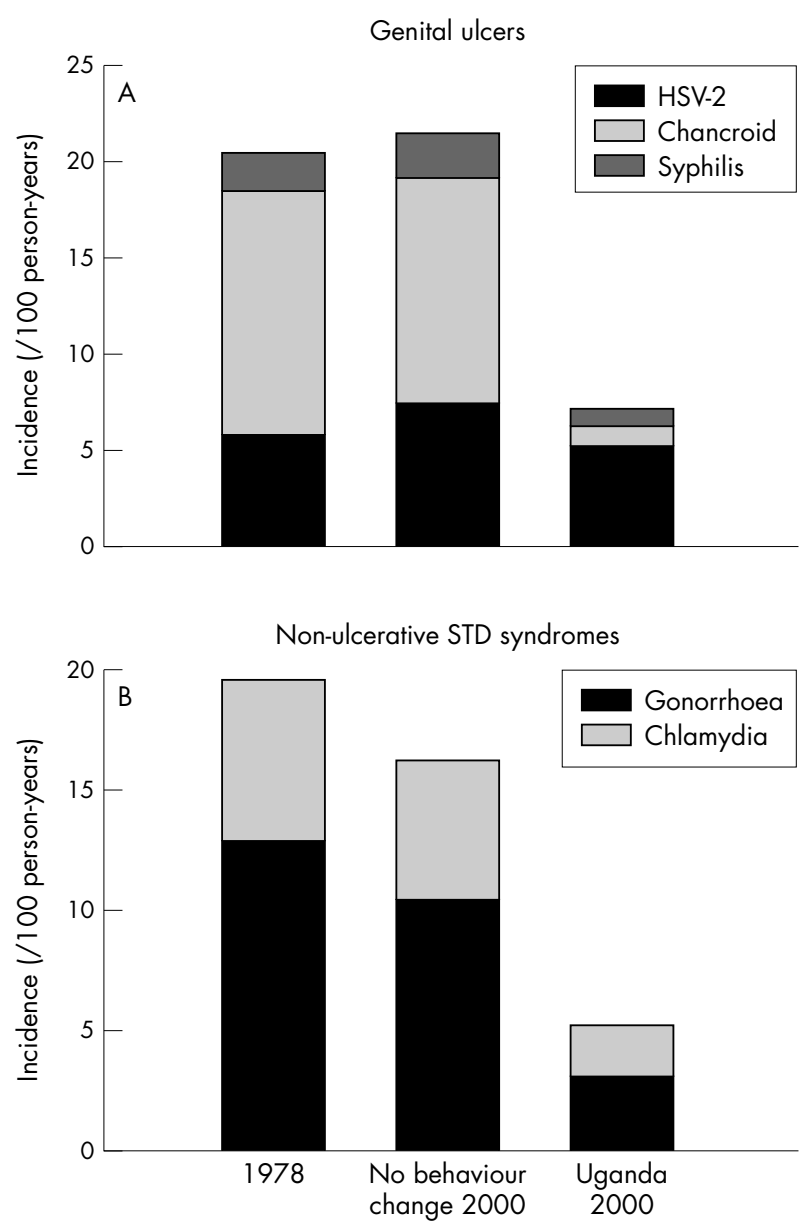

Figure 2 Distribution of recognised incident sexually transmitted disease (STD) syndromes over the different aetiologies before and during the HIV epidemic (calendar years 1978 and 2000, respectively) among adults ( 15 to 49 years) in the two simulated populations. (A) ulcerative STD; (B) non-ulcerative STD. Mean of 100 simulated populations. 
A
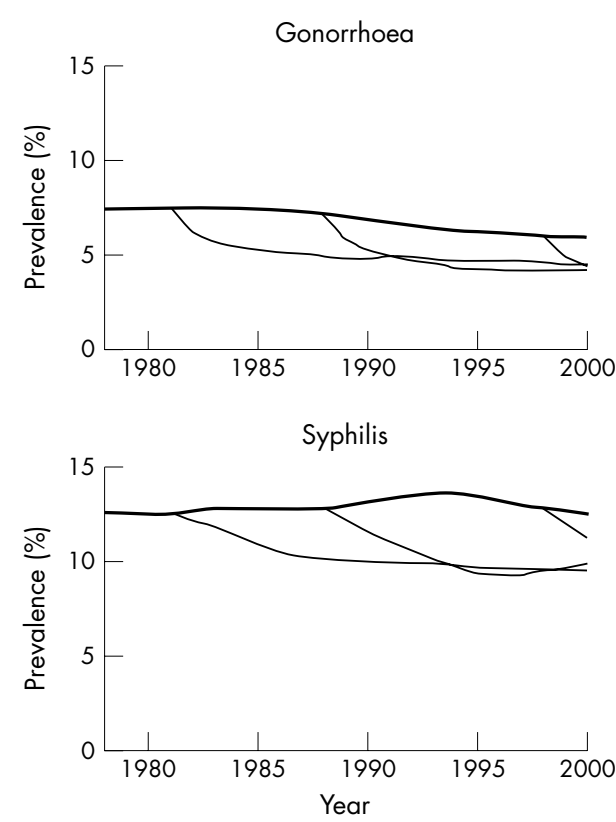

B
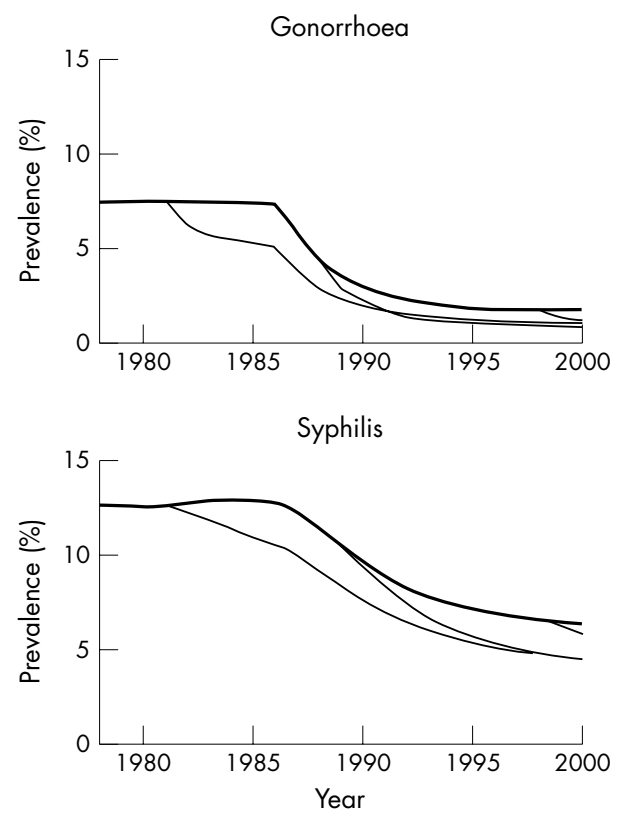

Chlamydia
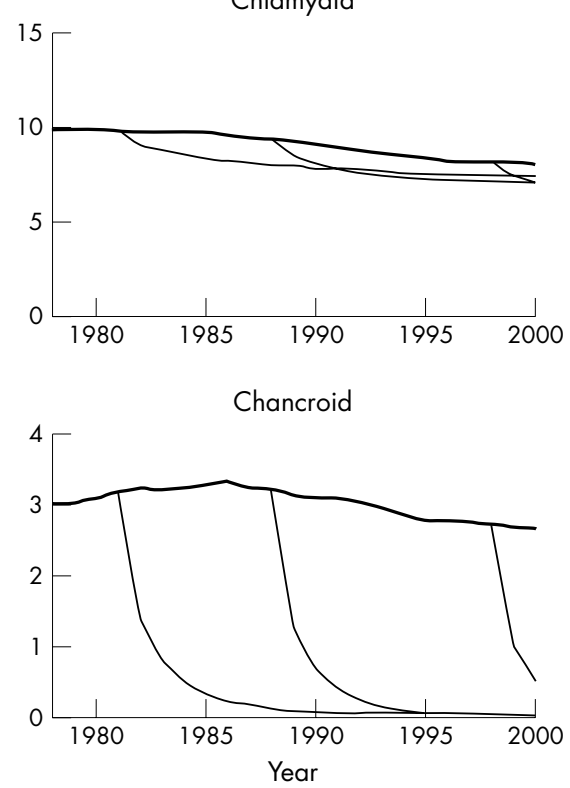

Figure 3 Impact of improved STD treatment intervention implemented in different stages of the HIV epidemic, in (A) the population without behavioural change; (B) Uganda, on the prevalences $(\%)$ of gonorrhoea, chlamydia, syphilis, and chancroid, in adults (15 to 49 years). Thick upper line in each graph: simulation without STD treatment; thin lines below: simulation with STD treatment implemented in (from left to right): year 3 , year 10 , and year 20 of the epidemic. Mean of 100 simulated populations. change, time trends in STD spectrum are in the same direction, but much less pronounced.

\section{Impact of STD treatment over time}

In the hypothetical population with unchanged behaviour, a programme of sustained improvement in STD treatment reduces STD prevalences considerably (fig 3A). The reduction is largest and fastest for chancroid. This is not only because of chancroid's relatively low reproductive number, but also because a large proportion of chancroid episodes are symptomatic (table 1) and hence amenable to syndromic treatment. The prevalence decline upon the start of improved STD treatment is comparatively slow and limited for syphilis. This reflects the long duration of the latent stage of syphilis, which counts as prevalent but does not cause genital symptoms (table 1) and is therefore not reached with syndromic approach.
In the Uganda simulation (fig 3B), STD interventions implemented after 1986 cause STD prevalences to fall less in absolute terms compared with the population without behaviour change, because prevalences have already been reduced before the STD intervention by behaviour change. As an overall result, the equilibrium STD rates during sustained STD treatment are much lower in the Ugandan population than in the hypothetical population without behaviour change. An exception is chancroid, which is also almost eradicated by the simulated improvement of STD treatment in the population with unchanged behaviour.

For both populations, the effect of improved treatment on STD prevalences is relatively similar at different time points of implementation. However, with later implementation the prevalence under sustained syndromic treatment is temporarily slightly lower than with earlier implementation, as can be seen in the crossing of the prevalence curves for all STD (fig 3). 
This is explained from an indirect effect of STD treatment on HIV spread, through a reduction in STD cofactor burden. With early implementation of improved STD management, HIV spread is reduced in the simulation (not shown); therefore the effect of selective HIV attributable mortality on STD prevalences is less marked, leaving higher STD prevalences.

The prevalence of herpes, which is not curable, is unaffected by improved syndromic treatment (not shown).

\section{DISCUSSION}

The simulations showed that severe HIV epidemics can affect STD epidemiology through multiple effects. Selective HIV attributable mortality in high risk groups decreases the occurrence of risk behaviours, and hence STD levels, on a population level. A more indirect effect ensues from behavioural risk reduction during the epidemic, as we inferred was the case for Uganda. Both effects are particularly strong for chancroid (fig l). Of all bacterial STDs, chancroid has the lowest reproductive number, making it relatively sensitive to control efforts or non-programme related behavioural changes. HSV-2 was least responsive to both selective mortality and behavioural risk reduction. This reflects its long duration, because of which changes in HSV-2 incidence or HIV related mortality affect HSV-2 seroprevalence relatively little. In addition, the high reproductive number resulting from the high baseline HSV-2 seroprevalence ensures that even after reductions in partner change rates, most uninfected individuals will sooner or later get exposed to at least one infected partner anyway.

In the simulations, behavioural change influenced STD epidemiology much more than the natural HIV dynamics. The relative magnitudes of these effects are, however, not known empirically, as they depend on unknown behavioural characteristics.

The epidemiology of STD and HIV in Uganda was best fitted by a model assuming considerable reductions in prostitution and in partner change rates after 1986. It in fact proved impossible to have STDSIM reproduce the observed decline in HIV prevalence in the 1990s without assuming some form of behaviour change in the late 1980s, for any combination of values for non-behavioural parameters codetermining HIV/ STD transmission dynamics and the rapidity of saturation of the HIV epidemic (simulations not shown). The best fit was obtained if the behaviour change was assumed to start in 1986. This change is compatible with the restored stability after the end of the Ugandan civil war in that year, and the subsequent adoption of the national AIDS control programme, or both. The resulting simulation outcomes provided reasonable fit against survey data on sexual behaviour and epidemiology from Rakai and other Uganda regions in the $1990 \mathrm{~s},{ }^{30-36}$ and they corroborate the conclusions from earlier models of Uganda. ${ }^{32}{ }^{40}$ However, the scarcity of survey data on the period before 1989 precludes certainty about whether the assumed type and strength of behaviour change was realistic. For example, it is conceivable that the risk level in the early 1980s was even higher than assumed, and the magnitude of behaviour change larger, or vice versa. Also, the behavioural change may in reality have been limited to a subset (or other types) of risk or protective behaviours as compared with those simulated. Simulations specifying changes in either prostitution or partnership change rates alone (and in varying degrees), however, indicate that the main conclusions would then be unaltered. Furthermore, it is unclear to what extent the behavioural trends in Uganda that coincided with the sociopolitical stabilisation are generalisable to other subSaharan African populations, although increasing numbers of sub-Saharan African countries have recently documented reduction in risk behaviour. ${ }^{31-33} 39$ 87-90

The effect of selective HIV mortality depends critically on supply and demand dynamics of sexual behaviour. ${ }^{91}{ }^{92}$ The
STDSIM model assumes that sexual promiscuity, represented as the frequency at which men have random one-off contacts with female sex workers, is a lifelong characteristic, which is not influenced by changes in sexual networks resulting from AIDS related mortality. For longer term partnerships, in contrast, supply and demand dynamics in the model cause non-promiscuous men and women to increase their partner change rate once the highest active individuals have died from AIDS. How realistic this choice is among the two extremes (totally individually determined or totally network determined) is unknown. Sensitivity analyses indicated that the magnitude of STD reduction from selective HIV-attributable mortality did not depend on the assumed STD/HIV cofactor effects (not shown).

A third effect of HIV on STD epidemiology is through immunosuppression during advanced HIV disease. ${ }^{1376}$ At a simulated magnitude of enhancement of herpetic ulceration by HIV disease effect estimated from clinical studies, the model predicted an unchanged HSV-2 seroprevalence level throughout the HIV epidemic for a population without behaviour change: the enhanced transmission from HIV patients just counterbalanced the decline in transmission caused by selective HIV related mortality. This perhaps unexpectedly small magnitude of effect in the general population has two main causes. First, most HSV-2 patients were not infected with HIV, because of the high prevalence of HSV-2 (48\%) relative to HIV (around 17\%). Even in a severe HIV epidemic, not all HSV-2 patients contract HIV, and those who do die earliest from HIV related mortality, which limits the combined prevalence. Second, the majority of partners of HSV-2/HIV patients are already infected with HSV-2, so that increased infectivity does not always actually increase transmission in the population. No data are available on HSV-2 seroprevalence over time periods spanning the course of sub-Saharan African HIV epidemics ${ }^{20}$ to support or refute the predicted lack of change in HSV-2 seroprevalence. Simulations with stronger effects of HIV would result in absolute increases during the HIV epidemic in HSV-2 seroprevalence. ${ }^{49}$ However, this would shift age peaks in HSV-2 seroprevalence toward the youngest age groups, which is inconsistent with findings from any recent sub-Saharan African serosurvey. ${ }^{93} 94$

As a result of the combined STD/HIV interactions, the HIV epidemic considerably shifted the spectrum of ulcerative STDs in the Uganda simulation (fig 2). A marked decrease in relative importance as a cause of GUD was predicted for chancroid. Genital herpes, by contrast, increased; and owing to the decrease in chancroid, syphilis became relatively more common as a bacterial cause of ulcers. The resulting simulated spectrum of ulcerative STDs for Uganda in the 1990s (fig 2A), with a predominance of HSV-2, is broadly consistent with empirical observations in rural Uganda ${ }^{83}$ and other subSaharan African populations suffering advanced HIV epidemics. ${ }^{68} 95$ In rural Rakai, over $80 \%$ of reported ulcers with known aetiology were attributable to HSV-2, $7.5 \%$ to chancroid, and around $10 \%$ to syphilis. $^{83}$ In Kampala, corresponding proportions were $88 \%, 9 \%$, and $4 \% .{ }^{96}$ The simulated decrease during the HIV epidemic in chancroid and relative increase in herpes can also explain ecological observations that African populations with severe HIV epidemics have less chancroid and more herpes among ulcer cases, and more ulcer cases compared with non-ulcer cases relative to populations with more limited HIV spread, ${ }^{20}{ }^{97-99}$ and it explains the apparent replacement of chancroid by HSV-2 as the predominant cause of ulcers in countries with severe HIV epidemics. ${ }^{18-21} 67$ 97 100-104

In the simulations, chancroid accounted for a larger proportion of diagnosed GUD ( $18 \%$ in 1995) than observed in Rakai at this time $(7.5 \%) .^{83}$ Several factors may explain this discrepancy. First, we may have underestimated the extent of behaviour change that occurred in this population. Furthermore, the assumed behaviour change in Rakai may in reality 
have involved not only reductions in partner change rates, but also increased condom use and improved treatment for curable STDs. As HSV-2 is incurable and condoms may be relatively ineffective against herpes transmission from herpetic ulcers occurring outside the genitals, these modes of risk reduction can be expected to affect chancroid (and syphilis) more than they affect HSV-2. Consequently, ignoring them in the model may have resulted in too small a shift in the aetiological distribution of GUD. Third, the Rakai aetiological distribution was based on fairly small numbers of samples tested, and the fractions thereof diagnosed as chancroid may by chance have been extremely low. Finally, lacking empirical data on the population prevalence of chancroid in Uganda, we cannot exclude the possibility that the simulated level of chancroid spread (fig 1D) was unrealistically high throughout the simulation.

Shifts in STD spectrum during the HIV epidemic have several implications for STD control. Importantly for clinical STD management, they may cause the sensitivity and specificity of earlier validated syndromic treatment algorithms to change. As more and more ulcers would be caused by herpes instead of chancroid and syphilis, syndromic treatment of ulcers with antibiotics-which cures syphilis and chancroid but not herpes-may become less cost-effective. Shifts among bacterial STDs might also dictate changes in treatment algorithms. For example, for settings with limited resources not allowing the prescription of more than one drug at a time, the relative increase in syphilis relative to chancroid might imply that the drug of first choice would no longer be ciprofloxacin (targeting chancroid), but penicillin (targeting syphilis). This illustrates the importance of monitoring the validity of treatment algorithms and the aetiology of GUD or genital discharge.

For outreach forms of STD control, it is relevant that the declines in prevalence cause STD to become more concentrated in core groups of individuals at high risk. For example, in our simulations, behavioural risk reduction increased the prevalence ratios for commercial sex workers relative to the general adult population from 10 to 23 for chancroid, and from 5 to 8 for syphilis, after 14 years. The retreat of STD into higher risk populations implies that strategies with respect to target groups may need to be reconsidered, and targeting of interventions to (the remaining) high risk groups is of undiminished importance.

\section{Conclusions}

In summary, comparing the various determinants of STD epidemiology, the behavioural change that seems to have occurred during the Uganda HIV epidemic was more influential in the simulations than the effects of selective HIV attributable mortality and HIV related immunosuppression on (herpetic) ulceration. Behaviour change also reduced STD rates more than programmes of improved STD management would probably have done. However, the simulations also showed that for high risk populations in which no change in sexual behaviour has yet occurred improved syndromic STD management can contribute considerably to lowering the burden of bacterial STDs, both in early and late stages of HIV epidemics. In all cases, care for STD patients provides a good entry for targeting HIV prevention activities to those at high risk.

\section{ACKNOWLEDGEMENT}

We thank Drs James Blanchard and Stephen Moses for useful comments on an earlier version of the manuscript. The STDSIM model was developed with support from The Commission of the European Communities (contract B7.6211/96/010). The current study was supported and financed by the Commission under contract B7.6211/97/ 017.

\section{Authors' affiliations}

E L Korenromp, R Bakker, J D F Habbema, Erasmus University Rotterdam, Department of Public Health, Rotterdam, Netherlands
R Gray, Johns Hopkins University School of Public Health, Department of Population and Family Health Sciences, Baltimore, USA

M J Wawer, Centre for Population and Family Health, Columbia

University School of Public Health, New York, USA

D Serwadda, Institute of Public Health, Makerere University, Kampala Uganda

\section{REFERENCES}

1 Piot P, Meheus A. [Epidemiology of sexually transmitted diseases in developing countries] Epidémiologie des maladies sexuellement transmissibles dans les pays en développement. Ann Soc Belg Med Trop 1983;63:87-110.

2 Lyons M. Sexually transmitted disease in the history of Uganda Genitourin Med 1994;70:138-45

3 Over $M$, Piot $P$. Human immunodeficiency virus infection and other sexually transmitted diseases in developing countries: public health importance and priorities for resource allocation. J Infect Dis 1996; 174:S162-75.

4 Belsey MA. The epidemiology of infertility: a review with particular reference to sub-Saharan Africa. Bull WHO 1976:54:319-41.

5 Caldwell JC, Caldwell P. The demographic evidence for the incidence and cause of abnormally low fertility in tropical Africa. World Health Stat Q 1983;36:2-34

6 Arya OP, Nsanzumuhire $H$, Taber SR. Clinical, cultural, and demographic aspects of gonorrhoea in a rural community in Uganda. Bull WHO 1973;49:587B95.

7 Verhagen AR, Gemert W. Social and epidemiological determinants of gonorrhoea in an East African country. Br J Vener Dis 1972;48:277-86.

8 Arya OP, Lawson JB. Sexually transmitted diseases in the tropics. Epidemiological, diagnostic, therapeutic, and control aspects. Trop Doct 1977;7:51-6.

9 Wasserheit JN, Aral SO. The dynamic topology of STD epidemics: implications for prevention strategies. J Infect Dis 1996;174/suppl 2):S201-13.

10 Kreiss JK, Coombs R, Plummer F, et al. Isolation of human immunodeficiency virus from genital ulcers in Nairobi prostitutes. J Infect Dis 1989;160:380-4

11 Cameron DW, Simonsen JN, D'Costa L, et al. Female to male transmission of human immunodeficiency virus type 1: risk factors for seroconversion in men. Lancet 1989;ii:403-7.

12 Laga M, Nzila N, Goeman J. The interrelationship of sexually transmitted diseases and HIV infection: implications for the control of both epidemics in Africa [review]. AIDA 1991;5:S55-63.

13 Wasserheit JN. Epidemiological synergy. Interrelationships between human immunodeficiency virus infection and other sexually transmitted diseases [review]. Sex Transm Dis 1992;19:61-77.

14 Laga M, Manoka A, Kivuvu M, et al. Non-ulcerative sexually transmitted diseases as risk factors for HIV-1 transmission in women: results from a cohort study. AIDS 1993;7:95-102.

15 Mostad SB, Kreiss JK. Shedding of HIV-1 in the genital tract [editorial review]. AIDS 1996;10:1305-15.

16 Fleming DT, Wasserheit JN. From epidemiological synergy to public health policy and practice: the contribution of other sexually transmitted diseases to sexual transmission of HIV infection. Sex Transm Inf 1999:75:3-17.

17 Goh CL. Chancroid - a review. Ann Acad Med 1987;16:680-2.

18 Dangor $Y$, Htun H, Radebe F, et al. Epidemiological, clinical and microbiological features of genital ulcer disease in Southern Africa influence of HIV infection. In: 13th meeting of the International Society for STD research (ISSTDR), Denver, Colorado, USA, 1999.

19 Steen R, DeCoito T, Ralepeli S, et al. Rapid control of chancroid in a South African mining company [abstract 337]. In: 13th Meeting of the International Society for Sexually Transmitted Diseases Research. Denver, Colorado, USA, 1999

20 O'Farrell N. Increasing prevalence of genital herpes in developing countries: implications for heterosexual HIV transmission and STI control programmes. Sex Transm Inf 1999;75:377-84.

21 De Coito T, Ralepeli S, Steen R, et al. Sustained reductions of STD in a South African mining community. In: 13th meeting of the International Society for STD research. Denver, Colorado, USA, 1999

22 Nahmias AJ, Lee FK, Beckman-Nahmias S. Sero-epidemiological and -sociological patterns of herpes simplex virus infection in the world. Scand J Infect Dis Suppl 1990:69:19-36.

23 Morse SA, Trees DL, Htun Y, et al. Comparison of clinical diagnosis and standard laboratory and molecular methods for the diagnosis of genital ulcer disease in Lesotho: association with human immunodeficiency virus infection. J Infect Dis 1997;175:583-9.

24 Chen CY, Ballard RC, Beck-Sague CM, et al. HIV infection and genita ulcer disease in South Africa. The herpetic connection. Sex Transm Dis 2000;27:21-9

25 Van der Ploeg CPB, Van Vliet C, De Vlas SJ, et al. STDSIM: a microsimulation model for decision support on STD control. Interfaces 1998;28:84-100

26 Korenromp EL, Van Vliet C, Bakker R, et al. HIV spread and partnership reduction for different patterns of sexual behaviour - a study with the microsimulation model STDSIM. Math Popul Stud 2000;8:135-73.

27 Serwadda D, Sewankambo NK, Carswell JW, et al. Slim disease: a new disease in Uganda and its association with HTLV-III infection. Lancet 1985;ii:849-52. 
28 Sewankambo NK, Wawer M, Gray RH, et al. Demographic impact of HIV infection in rural Rakai district, Uganda: results of a population-based cohort study. AIDS 1994;8:1707-13.

29 Sewankambo NK, Carswell JW, Mugerwa RD, et al. HIV infection through normal heterosexual contact in Uganda. AIDS 1987;1:113-16.

30 Konde-Lule JK, Wawer M, Sewankambo NK, et al. Adolescents, sexual behaviour and HIV-1 in rural Rakai district, Uganda. AIDS 1997;11:791-9.

31 Asiimwe-Okiror G, Opio AA, Musinguzi J, et al. Change in sexual behaviour and decline in HIV infection among young pregnant women in urban Uganda. AIDS 1997;11:1757-63.

32 Kilian AhD, Gregson S, Ndyanabangi B, et al. Reductions in risk behaviour provide the most consistent explanation for declining HIV-1 prevalence in Uganda. AIDS 1999;13:391-8.

33 Kamali A, Carpenter LM, Whitworth JA, et al. Seven-year trends in HIV-1 infection rates, and changes in sexual behaviour, among adults in rural Uganda. AIDS 2000;14:427-34.

34 Pool R, Boerma JT, Maswe $M$, et al. Changes in male sexual behaviour in response to the AIDS epidemic. 2. Validation of reported changes. Mwanza: TANESA project to support HIV/AIDS control, 1995

35 Kaijuka EM, Kaija EZA, Cross AR, et al. Uganda demographic and health survey 1988/1989. Entebbe: Ministry of Health, in collaboration with Ministry of Planning and Economic Development, Department of Geography and Institute of Statistics and Applied Economics, Makerere University, and Institute for Resource Development/Macro Systems Inc, Columbia, Maryland USA, 1989.

36 Statistics Department, Uganda MII. Uganda demographic and health survey, 1995. Entebbe: Statistics Department, Uganda and Macro International Inc, Calverton, Maryland, USA, 1996.

37 Mulder DW, Nunn A, Kamali A, et al. Decreasing HIV-1 seroprevalence in young adults in a rural Ugandan cohort. BM 1995;311:833-6.

38 Konde-Lule JK. The declining HIV seroprevalence in Uganda: what evidence? Health Transition Rev 1995;5(suppl):27-33.

39 Wawer MJ, Serwadda D, Gray RH, et al. Trends in HIV-1 prevalence may not reflect trends in incidence in mature epidemics: data from the Rakai population-based cohort, Uganda. AIDS 1997;11:1023-30.

40 Stoneburner RL, Low-Beer D, Tembo GS, et al. Human immunodeficiency virus infection dynamics in east Africa deduced from surveillance data. Am J Epidemiol 1996;144:682-95

41 Korenromp EL, Van Vliet C, Grosskurth H, et al. Model-based evaluation of single-round mass STD treatment for HIV control in a rural African population. AIDS 2000;14:573-93.

42 Wawer MJ, Serwadda D, Musgrave SD et al. Dynamics of spread of HIV-I infection in a rural district of Uganda. BMV 1991;303:1303-6.

43 Wawer MJ, Sewankambo NK, Berkley S, et al. Incidence of HIV-1 infection in a rural region of Uganda [see comments]. BM 1994;308: 171-3.

44 Wawer MJ, Gray RH, Sewankambo NK, et al. A randomized community trial of intensive sexually transmitted disease control for AIDS prevention, Rakai, Uganda. AIDS 1998;12:1211-25.

45 Serwadda D, Wawer M, Musgrave SD, et al. HIV risk factors in three geographic strata of rural Rakai District, Uganda [see comments]. AIDS 1992;6:983-9.

46 Grosskurth H, Mosha F, Todd J, et al. Impact of improved treatment of sexually transmitted diseases on HIV infection in rural Tanzania: randomised controlled trial. Lancet 1995;346:530-6.

47 Grosskurth H, Gray R, Hayes R, et al. Control of STDs for HIV prevention: understanding the implications of the Mwanza and Rakai trials [viewpoint paper]. Lancet 2000;355:1981-7.

48 Barongo LR, Borgdorff MW, Mosha FF, et al. The epidemiology of HIV-1 infection in urban areas, roadside settlements and rural villages in Mwanza region, Tanzania. AIDS 1992;6:1521-8.

49 Korenromp EL, Bakker R, De Vlas SJ, et al. Can behaviour change explain increases in the proportion of genital ulcers attributable to herpes in sub-Saharan Africa? A simulation modelling study. Sex Transm Dis (in press)

50 Rawls WE, Gardner HL, Flanders RW, et al. Genital herpes in two social groups. Am J Obstet Gynecol 1971;1 10:682-9.

51 Corey L, Adams HG, Brown ZA, et al. Genital herpes simplex virus infections: clinical manifestations, course, and complications. Ann Intern Med 1983;98:958-72

52 Cone RW, Hobson AC, Palmer J, et al. Extended duration of herpes simplex virus DNA in genital lesions detected by the polymerase chain reaction. J Infect Dis 1991;164:757-60.

53 Koelle DM, Benedetti J, Langenberg A, et al. Asymptomatic reactivation of herpes simplex virus in women after the first episode of genital herpes. Ann Intern Med 1992;116:433-7.

54 Corey L, Benedetti J, Critchlow C, et al. Treatment of primary first-episode genital herpes simplex virus infections with acyclovir: results of topical, intravenous and oral therapy. J Antimicrob Chemother 1983;12 (suppl B):79-88

55 Wald A, Zeh J, Selke S, et al. Reactivation of genital herpes simplex virus type 2 infection in asymptomatic seropositive persons. N Engl J Med 2000;342:844-50.

56 Langenberg A, Benedetti J, Jenkins J, et al. Development of clinically recognizable genital lesions among women previously identified as having "asymptomatic" herpes simplex virus type 2 infection. Ann Intern Med 1989;110:882-7

57 Adam E, Kaufman RH, Mirkovic RR, et al. Persistence of virus shedding in asymptomatic women after recovery from herpes genitalis. Obstet Gynecol 1979;54:171-3

58 McCaughtry ML, Fleagle GS, Docherty JJ. Inapparent genital herpes simplex virus infection in college women. J Med Virol 1982;10:283-90.
59 Corey L. The current trend in genital herpes. Progress in prevention. Sex Transm Dis 1994:21:S38-44.

60 Wald A, Zeh J, Selke S, et al. Virologic characteristics of subclinical and symptomatic genital herpes infections. N Engl J Med 1995;333:770-5.

61 Wald A, Corey L, Cone R, et al. Frequent genital herpes simplex virus 2 shedding in immunocompetent women. Effect of acyclovir treatment. J Clin Invest 1997;99:1092-7.

62 Rauschkolb JE. Circumcision in treatment of chancroidal lesions of male genitalia. Arch Dermatol Syph 1939;39:319-28

63 Hanschell HM. Sulphanilamide in the treatment of chancroid. Lancet 1938;i:886-8.

64 Plummer FA, D'Costa L, Nsanze H, et al. Epidemiology of chancroid and Haemophilus ducreyi in Nairobi, Kenya. Lancet 1983; ii: 1293-5.

65 Holmes KK, Mardh P-A, Sparling PF, et al, eds. Sexually transmitted diseases, 3rd ed. New York: McGraw-Hill, 1999.

66 DiCarlo RP, Martin DH. The clinical diagnosis of genital ulcer disease in men [see comments]. Clin Infect Dis 1997;25:292-8.

67 Bogaerts J, Ricart CA, Van Dyck E, et al. The etiology of genital ulceration in Rwanda. Sex Transm Dis 1989;16:123-6.

68 Le Bacq F, Mason PR, Gwanzura L, et al. HIV and other sexually transmitted diseases at a rural hospital in Zimbabwe. Genitourin Med 1993;69:352-6.

69 Levy JA. The transmission of HIV and factors influencing progression to AIDS [review]. Am J Med 1993;95:86-91.

70 Jacquez JA, Koopman JS, Simon CP, et al. Role of the primary infection in epidemics of HIV infection in gay cohorts [review]. J Acquir Immune Defic Syndr 1994:7:1 169-84.

71 De Vincenzi I, for the European study group on heterosexual transmission of HIV. A longitudinal study of HIV transmission by heterosexual partners. N Engl J Med 1994;331:341-6.

72 Morgan D, Maude GH, Malamba SS, et al. HIV-1 disease progression and AIDS-defining disorders in rural Uganda. Lancet 1997;350:245-50.

73 Gray RH, Wawer M, Brookmeyer R, et al. Probability of HIV-1 transmission per coital act in monogamous, heterosexual, HIV-1-discordant couples in Rakai, Uganda. Lancet 200 1;357:1 149-53.

74 Hayes RJ, Schulz KF, Plummer FA. The cofactor effect of genital ulcers on the per-exposure risk of HIV transmission in sub-Saharan Africa [review]. J Trop Med Hyg 1995:98: 1-8.

75 Korenromp EL, De Vlas NJ, Nagelkerke NJD, et al. Estimating the magnitude of STD cofactor effects on HIV transmission - how well can it be done? Sex Transm Dis 2001;11:613-21.

76 Wald A, Corey L, Handsfield HH, et al. Influence of HIV infection on manifestations and natural history of other STDs. Annu Rev Public Health 1993; 14:19-42.

77 Augenbraun M, Feldman J, Chirgwin K, et al. Increased genital shedding of HSV type 2 in HIV-seropositive women. Ann Intern Med 1995; 123:845-7.

78 Hitti J, Watts DH, Burchett SK, et al. Herpes simplex virus seropositivity and reactivation at delivery among pregnant women infected with human immunodeficiency virus-1. Am J Obstet Gynecol 1997; 177:450-4.

79 Schacker T, Zeh J, Hu HL, et al. Frequency of symptomatic and asymptomatic herpes simplex virus type 2 reactivations among human immunodeficiency virus-infected men. J Infect Dis 1998;178:1616-22.

80 Mbopi-Keou F-X, Grésenguet G, Mayaud P, et al. Genital HSV-2 shedding is increased in HIV-infected women in Africa. AIDS 1999; 13:536-7.

81 Kaul R, Kimani J, Nagelkerke NJD, et al. Risk factors for genital ulcerations in Kenyan sex workers. The role of HIV-1 infection. Sex Transm Dis 1997:24:387-92.

82 Buvé A, Gavyole A, Mugeye K, et al. A closer look at the intervention of the Mwanza trial: how many patients with an STD are cured by health services? In: 12th World AIDS conference. Geneva, 1998.

83 Wawer MJ, Sewankambo NK, Serwadda D, et al. Control of sexually transmitted diseases for AIDS prevention in Uganda: a randomised community trial. Lancet 1999:353:525-35.

84 Kamali A, Nunn AJ, Mulder DW, et al. Seroprevalence and incidence of genital ulcer infections in a rural Ugandan population. Sex Transm Inf 1999:75:98-102.

85 Brunham RC, Plummer FA. A general model of sexually transmitted disease epidemiology and its implications for control. Med Clin North Am 1990;74:1339-52

86 Stoneburner R, Carballo M, Bernstein R, et al. Simulation of HIV incidence dynamics in the Rakai population-based cohort, Uganda. AIDS $1998 ; 12: 226-8$

$87 \mathbf{~ N g}$ 'weshemi JZL, Boerma JT, Pool R, et al. Changes in male sexual behaviour in response to the AIDS epidemic: evidence from a cohort study in urban Tanzania. AIDS 1996;10:1415-20.

88 Jackson DJ, Rakwar JP, Richardson BA, et al. Decreased incidence of sexually transmitted diseases among trucking company workers in Kenya: results of a behavioural risk-reduction programme. AIDS 1997;11:903-9.

89 Gregson S, Zhuwau T, Anderson RM, et al. Is there evidence for behaviour change in response to AIDS in rural Zimbabwe? Soc Sci Med 1998;46:321-30

90 Meekers D. Going underground and going after women: trends in sexual risk behaviour among gold miners in South Africa. Int J STD AIDS 2000;1 1:21-6.

91 Le Pont F, Blower SM. The supply and demand of sexual behavior: implications for heterosexual HIV epidemics. J Acquir Immun Defic Syndr 1991;4:987-99.

92 Boily M-C, Anderson RM. Sexual contact patterns between men and women and the spread of HIV-1 in urban centres in Africa. IMA J Math Appl Med Biol 1991;8:221-47. 
93 McFarland W, Gwanzura L, Bassett MT, et al. Prevalence and incidence of herpes simplex virus type 2 infection among male Zimbabwean factory workers. J Infect Dis 1999; 180:1459-65.

94 Robinson NJ, Hosseini M. Age-specific herpes simplex virus type 2 seroprevalence in general populations: estimates from around the globe. In: MSSVD/ASTDA STI at the millennium conference. Baltimore, 2000.

95 Behets FMT, Liomba G, Lule G, et al. Sexually transmitted diseases and HIV control in Malawi: a field study of genital ulcer disease. J Infect Dis 1995; 171:451-5.

96 Kamya MR, Nsubuga P, Grant RM, et al. The high prevalence of genital herpes among patients with genital ulcer disease in Uganda. Sex Transm Dis 1995;22:351-4

97 Haines M, Goldsmid JM, Kennedy S. A study of gonorrhoea in the Rhodesian African. Cent Afr J Med 1978;24:140-4.

98 Meheus A, Van Dyck E, Ursi JP, et al. Etiology of genital ulcerations in Swaziland. Sex Transm Dis 1983;10:33-5.
99 O'Farrell N. High prevalence of genital ulcers in countries worst affected by HIV in Africa. In: XIllth International AIDS conference. Durban, 2000.

100 Fast MV, D'Costa $\mathrm{W}, \mathrm{Nsanze} H$, et al. The clinical diagnosis of genital ulcer disease in men in the tropics. Sex Transm Dis 1984;11:72-6.

101 Hazlett DTG, Bowmer MI, Nsanze H, et al. Herpes simplex virus in clinically suspected chancroid in Nairobi, Kenya. Afr J Sex Transm Dis 1984;1:16-18

102 Plummer FA, D'Costa L, Nsanze H, et al. Clinical and microbiologic studies of genital ulcers in Kenyan women. Sex Transm Dis 1985;12:193B7.

103 Greenblatt RM, Lukehart SA, Plummer FA, et al. Genital ulceration as a risk factor for HIV infection. AIDS 1988;2:47-50.

104 Bogaerts J, Kestens L, van Dyck E, et al. Genital ulcers in a primary health clinic in Rwanda: impact of HIV infection on diagnosis and ulcer healing (1986-1992). Int J STD AIDS 1998;9:706-10. 